\title{
Decolonialidade e relações raciais: um olhar sobre o ensino de História no currículo do curso de Pedagogia da UFRGS
}

\author{
Decoloniality and racial relationships: a look at history teaching in the UFRGS Pedagogy \\ course curriculum
}

\author{
Eduarda Souza Gaudio \\ Doutoranda em Educação pela Universidade Federal de Santa Catarina \\ eduardagaudio@gmail.com
}

Joana Célia dos Passos

Doutorado em Educação (2010) pela Universidade Federal de Santa Catarina (UFSC) com pós doutorado em Sociologia Política. passos.jc@gmail.com

Resumo: O artigo evidencia a insurgência do Movimento Negro pela descolonização dos currículos, por meio da construção de uma política para a educação das relações étnicoraciais e as implicações aos cursos de Pedagogia. Além disso, apresenta as alterações promovidas no currículo do curso de Pedagogia da Universidade Federal do Rio Grande do Sul (UFRGS), focalizando as perspectivas assumidas pelo ensino de História. Para a realização do estudo, realizouse uma análise documental do Projeto Politico Pedagógico do curso e dos Programas das disciplinas, a partir de categorias que buscaram identificar as perspectivas epistemológicas assumidas no projeto do curso. As análises demonstraram a presença de componentes curriculares que possibilitam discussões, conteúdos e temáticas potencializadoras de uma perspectiva decolonial.

Palavras-chave: Decolonialidade; Relações Raciais; Ensino de História.

\begin{abstract}
The article highlights the Black Movement's insurgency by the decolonization of curricula, through the construction of a policy for the education of ethnic-racial relations and the implications for Pedagogy courses. In addition, it presents the changes promoted in the curriculum of the Pedagogy course at the Federal University of Rio Grande do Sul (UFRGS), focusing on the perspectives assumed by the teaching of History. In order to carry out the study, a documentary analysis of the Pedagogical Political Project of the course and the Programs of the disciplines was carried out, from categories that sought to identify the epistemological perspectives assumed in the course project. The analyzes demonstrated the presence of curricular components that enable discussions, content and themes that enhance a decolonial perspective.
\end{abstract}

Keywords: Decoloniality; Race Relations; History Teaching 


\section{Considerações Iniciais}

"[...] tenhamos esperança, a intelectualidade negra sempre existiu, e nós estamos aqui testemunhando o legado de nossa ancestralidade: As Civilizações Tradicionais Africanas" (SIQUEIRA, 2006).

Cada vez mais, pesquisadores/as, estudiosos/as e integrantes de grupos sociais problematizam as violências geradas pelo processo de colonização que os continentes Americano, Asiático e Africano foram submetidos, procurando "captar as continuidades, rupturas e complexidades específicas de períodos históricos, na tentativa de ir além das concepções cronológicas estritas, lineares e dicotômicas" (MENESES, 2010: 222). Tais abordagens inflexionam as relações de poder instauradas por um sistema colonial em que a violência, interseccionada com as demarcações de raça, gênero e sexo, constituiu-se como elemento central no processo de desumanização dos sujeitos colonizados (FANON, 2005).

O processo de colonização pelo qual os países da América foram submetidos resultou na supressão de saberes e conhecimentos por uma racionalidade científica que nos impossibilitou de conhecer nossas próprias histórias. As populações colonizadas, entre elas indígenas, quilombolas e negros/as, foram privadas das narrativas que constituíram suas identidades sociais, culturais e raciais, através da imposição de um saber considerado superior.

Frente ao sistema colonial, racista e heteropatriarcal estabelecido pela modernidade, insurgem movimentos protagonizados pelas populações negras, indígenas e quilombolas que denunciam as violências e injustiças produzidas pelo processo colonial, buscando reconhecer perspectivas outras de pensar e produzir conhecimento. No Brasil, a luta pela vida e sobrevivência demarcou a história de crianças, jovens, mulheres e homens, negros e negras, num processo por resistir e reexistir ao genocídio e epistemicídio instaurados no processo colonial e atualizados pela colonialidade.

Os pensamentos pós-coloniais e decoloniais serão assumidos como um conjunto amplo e heterogêneo de estudos e proposições elaboradas por diferentes áreas e grupos num esforço coletivo de construir referências epistemológicas que contestem os 
paradigmas estabelecidos pela modernidade ${ }^{1}$. No entanto, evidenciamos em primeiro plano as ações e os movimentos de resistência da população negra, considerando os mais de 500 anos de luta efetuadas por sujeitos e/ou organizações coletivas em diáspora africana.

A partir de uma compreensão abrangente desses campos de estudos e não meramente a um recorte temporal, a decolonialidade será admitida a partir do processo histórico de lutas e resistências dos sujeitos afrodiaspóricos (BERNARDINO-COSTA, MALDONADO-TORRES, GROSFOGUEL, 2019), sobretudo daqueles/as articulados/as ao Movimento Negro, que atua teórica e politicamente na luta pela igualdade racial, contribuindo para a construção de uma perspectiva decolonial que questiona a subalternização dos conhecimentos produzidos pela população negra e cria estratégias políticas para a descolonização dos currículos.

Nesse sentido, o artigo pretende evidenciar as proposições educacionais elaboradas pelo Movimento Negro, sobretudo a política para a educação das relações étnico-raciais e as implicações destas nos cursos de Pedagogia. A partir das determinações advindas dessa política, apresentaremos as alterações promovidas no currículo do curso de Pedagogia da Universidade Federal do Rio Grande do Sul (UFRGS), focalizando o ensino de História que integra a matriz curricular do curso. Pretendemos assumir as mudanças como alternativas epistemológicas de um movimento que contribui com a descolonização dos conhecimentos, dos currículos e da própria Pedagogia.

O presente texto é parte da pesquisa de doutorado que buscou compreender os processos de institucionalização da educação das relações étnico-raciais nos currículos dos cursos de Pedagogia de três universidades federais do Sul do Brasil: Universidade Federal do Rio Grande do Sul (UFRGS), Universidade Federal de Santa Catarina (UFSC) e Universidade Federal do Paraná (UFPR)². Para a realização da pesquisa, analisamos os documentos curriculares produzidos pelas três instituições, especialmente os Projetos Políticos Pedagógicos dos cursos e os Programas e Planos de Ensino das disciplinas. Além disso, optamos por entrevistar professores/as responsáveis por propor e ministrar

\footnotetext{
${ }^{1}$ Para Maldonado-Torres (2019) “a descolonização refere-se a momentos históricos em que os sujeitos coloniais se insurgiram contra os impérios e reivindicaram a independência, a decolonialidade refere-se à luta contra a lógica da colonialidade e seus efeitos materiais, epistêmicos e simbólicos. Às vezes o termo descolonização é usado no sentido de decolonialidade. Em tais casos, a descolonização é tipicamente concebida não como uma realização ou um objetivo pontual, mas sim como um projeto inacabado" (MALDONADO-TORRES, 2019: 36).

2 Para maiores informações consultar o trabalho na integra (GAUDIO, 2021).
} 
disciplinas com enfoque racial no curso de Pedagogia, procurando visibilizar os sujeitos que protagonizaram o debate das relações raciais no currículo.

Para a escrita do artigo concentramos nosso olhar no Projeto Político Pedagógico e Programas das disciplinas do curso de Pedagogia da UFRGS com a intenção de percebermos em que medida a crítica colonial se faz presente. Como lentes de análise, utilizamos as seguintes categorias: "relações étni*-raci*, história e cultura africana e afrobrasileira, de(s)colonial* e intercultural ${ }^{*}{ }^{\prime 3}$. No que tange ao componente curricular de História, o curso de Pedagogia da UFRGS é o único, dentre as três instituições pesquisadas, que menciona essas categorias nas súmulas das disciplinas, anunciando a perspectiva decolonial como parte do projeto de curso.

\section{Pensamento negro decolonial e Educação}

A despeito da produção científica que fundamenta os estudos decoloniais ter culminado na academia recentemente, consideramos as estratégias políticas criadas pela população negra como formas de reagir à dominação e exploração, anunciando suas existências, através de ocupações, atos, marchas e mobilizações pelas quais manifestam seus pertencimentos (GOMES, 2019). Por mais de cinco séculos, sujeitos afrodiaspóricos movimentam-se em face a um sistema de opressão, denunciando as violências e desigualdades e criando proposições políticas e sociais em prol de direitos de negros e negras na sociedade brasileira.

No entanto, as ações elaboradas por negras e negros têm sido pouco consideradas no âmbito da produção do conhecimento, inclusive dentro das perspectivas inscritas como decoloniais que acabam delimitando-se a um conjunto de referenciais que propõe um "giro colonial", mas acabam conseguindo dar somente "meia voltinha" (LIMA e SILVA, 2020) ao desconsiderarem as epistemologias negras. A justificativa para esse apagamento deve-se ao epistemicídio, compreendido por Sueli Carneiro (2005) como um processo que busca negar, inferiorizar e desqualificar a condição da população negra como produtora de conhecimento.

Nesse artigo, assumimos as práticas de resistência política, teórica e epistemológica criadas por sujeitos e grupos vinculados ao Movimento Negro que possui ampla atuação na luta por direitos sociais. Balizadas por Nilma Lino Gomes (2017),

\footnotetext{
${ }^{3}$ Utilizamos o caractere curinga “*” em alguns termos para possibilitar a busca de outras categorias semelhantes.
} 
consideramos o Movimento Negro como educador, constituído pelas "mais diversas formas de organização e articulação das negras e dos negros politicamente posicionados na luta contra o racismo e que visam à superação desse perverso fenômeno na sociedade" (GOMES, 2017: 23).

As epistemologias negras têm origem nas experiências sociais, nas periferias, nas práticas cotidianas, na ressignificação e reinvenção das identidades e culturas e nas possibilidades de intervir criticamente na realidade (HOOKS, 2013). Tal produção vem constituindo o que Gomes (2019) vai chamar de perspectiva negra decolonial brasileira, responsável pelo processo de descolonização dos conhecimentos e, consequentemente, dos currículos educacionais.

A ressignificação da ideia de "raça" foi um elemento central na produção do pensamento negro brasileiro que se apropria politicamente desse conceito como uma construção social utilizada como lente de análise das relações de poder, das desigualdades sociais, dos privilégios da branquitude e do racismo estrutural que demarca nossa sociedade. Logo, as análises elaboradas pela perspectiva negra decolonial nascem problematizando a ideologia racial instaurada no pós-Abolição, precedendo a reconhecida produção elaborada por Aníbal Quijano (2010) acerca da colonialidade do poder que compreende o racismo como princípio organizador das lógicas da modernidade.

Ao politizar a noção de raça, o Movimento Negro inicia um processo de denúncias das desigualdades sociais brasileiras e de reivindicações pelo acesso aos espaços institucionais públicos. A educação, direito historicamente conquistado pela população negra, é escolhida como espaço prioritário de atuação desses movimentos com vistas a intervir na realidade social, buscando a emancipação dos sujeitos historicamente subalternizados. Levando em consideração a importância das estratégias efetuadas nesse âmbito, passaremos a apresentar as principais ações ${ }^{4}$ que resultaram na política de educação das relações étnico-raciais.

A década de 1990 foi marcada por movimentações políticas, sociais e econômicas ocorridas nacional e internacionalmente, sobretudo com as reformas constitucionais elaboradas por muitos países que lutavam pela construção de um Estado democrático de

\footnotetext{
4 Para esse artigo, privilegiamos as ações ocorridas no final do século XX, mas consideramos que os movimentos que antecederam esse recorte temporal trouxeram mudanças significativas na luta antirracista. Gomes (2017) destaca algumas ações centrais, elaboradas no início do século XX, como a imprensa negra paulista, em 1916, a Frente Negra Brasileira, em 1931, e o Teatro Experimental do Negro (TEN), em 1944 Outro marco crucial na luta contra o racismo foi a fundação do Movimento Negro Unificado (MNU), em 1978, criado para coletivizar as demandas de diversas entidades negras do país.
} 
direito. Joana Célia dos Passos e João Carlos Nogueira (2014) enfatizam que a militância negra percorreu um processo de enfrentamento das desigualdades raciais, de denúncia ao racismo e de fortalecimentos dos coletivos associando-se a diversas esferas sociais. As conciliações realizadas entre o Movimento Negro e partidos políticos, movimentos sindicais e organizações não governamentais consolidaram um conjunto de objetivos e estratégias de promoção da igualdade racial. A articulação entre os movimentos sociais possibilitaram uma unidade acerca das diferentes lutas contra o racismo, sexismo e machismos, fortalecendo e ampliando as frentes em oposição a todas as formas de discriminação.

Um marco na luta do Movimento Negro foi a I Marcha Nacional Zumbi dos Palmares, realizada em Brasília, no ano de 1995, que culminou na entrega do "Programa para superação do racismo e da desigualdade étnico-racial" ao presidente da República. Em 2001, a participação do Movimento Negro na organização e realização da III Conferência Mundial contra o Racismo, a Discriminação Racial, a Xenofobia e Formas Correlatas de Intolerância, ocorrida em Durban, na África do Sul, representou um momento imperativo no reconhecimento da existência do racismo no Brasil. A partir desse acontecimento, o país passa a se comprometer com a construção de estratégias que buscam promover a igualdade racial, por meio da criação de políticas de ações afirmativas.

A constituição da Associação Brasileira de Pesquisadores/as Negros/as (ABPN) também pode ser considerada uma importante estratégia no âmbito da produção acadêmica. Composta por estudiosos/as que trabalham com temas referentes as questões raciais, focalizadas na s população negra no Brasil, a associação fundada em 2000 realiza o Congresso de Pesquisadores/as Negros/as (COPENE) ${ }^{5}$ que reúne associados/as em ações de articulação, divulgação, promoção, valorização e construção de uma agenda nacional voltada aos estudos africanos e afro-brasileiros.

Em 2003, a discussão alcança a estrutura do Estado, por meio da criação da Secretaria de Políticas de Promoção da Igualdade Racial (Seppir) e, no ano seguinte, no âmbito do Ministério da Educação (MEC), a Secretaria de Educação Continuada, Alfabetização e Diversidade (Secad). Nesse período é sancionada a Lei 10.639/2003 que alterou a LDB/96 instituindo a história e cultura africana e afro-brasileira nas instituições

\footnotetext{
5 Para maiores informações sobre a Associação e o Congresso ver: https://www.abpn.org.br/.
} 
escolares, modificada novamente pela Lei 11.645/2008, integrando a temática indígena nos currículos.

Como forma de subsidiar a implementação dessas deliberações foram elaboradas uma série de documentos e materiais, em âmbito nacional, que orientam o trabalho com a discussão étnico-racial em todas as etapas, modalidades e níveis de ensino. Entre eles destacamos: as Diretrizes Curriculares Nacionais para a Educação das Relações ÉtnicoRaciais e para o Ensino de História e Cultura Afro-Brasileira e Africana (2004), as Orientações e Ações para a Educação das Relações Étnico-Raciais (2006), o Plano Nacional de Implementação das Diretrizes Curriculares Nacionais para a Educação das Relações Étnico-Raciais (2009), as Diretrizes Curriculares Nacionais para a Educação Escolar Quilombola (2012) e as Diretrizes Curriculares Nacionais para a Educação Escolar Indígena (2012).

As Diretrizes Curriculares Nacionais para a Educação das Relações ÉtnicoRaciais e para o de Ensino de História e Cultura Afro-Brasileira e Africana (2004), composto pelo Parecer CNE/CP n 003/2004 e Resolução no 01/2004, busca orientar e fundamentar o trabalho pedagógico, tendo como meta "[...] promover a educação de cidadãos atuantes e conscientes no seio da sociedade multicultural e pluriétnica do Brasil, buscando relações étnico-sociais positivas, rumo à construção de nação democrática" (BRASIL, 2004: 01).

O documento apresenta a proposta de uma reeducação das relações étnico-raciais indicando um conjunto de possibilidades de se relacionar com os diferentes grupos sociais que compõe a sociedade. Conforme os incisos $1^{\circ}$ e $2^{\circ}$, do artigo $2^{\circ}$

§ A Educação das Relações Étnico-Raciais tem por objetivo a divulgação e produção de conhecimentos, bem como de atitudes, posturas e valores que eduquem cidadãos quanto à pluralidade étnico-racial, tornando-os capazes de interagir e de negociar objetivos comuns que garantam, a todos, respeito aos direitos legais e valorização de identidade, na busca da consolidação da democracia brasileira.

$\S 2^{\circ} \mathrm{O}$ Ensino de História e Cultura Afro-Brasileira e Africana tem por objetivo o reconhecimento e valorização da identidade, história e cultura dos afro-brasileiros, bem como a garantia de reconhecimento e igualdade de valorização das raízes africanas da nação brasileira, ao lado das indígenas, europeias, asiáticas (BRASIL, 2004: 01). 
Importante destacar que as orientações apresentadas pelas DCNERER não propõem a substituição do foco etnocêntrico de base europeia por uma africana, mas busca que os projetos e programas curriculares ampliem suas perspectivas de modo a possibilitar que a diversidade racial, cultural e econômica que constituem a sociedade brasileira seja também foco dos estudos Esses conteúdos e conhecimentos devem ser instituídos não só nos espaços de educação básica, como também no ensino superior, incluindo os cursos de licenciaturas, buscando formar professores/as para a diversidade étnico-racial.

As determinações trazidas pelas Diretrizes tornam o ensino superior como um dos níveis de educação responsável pela inclusão de conteúdos acerca da história e cultura africana e afro-brasileira, dos conceitos que abrangem o racismo, as discriminações, a diferença, o preconceito, a etnia, a classe, entre outros assuntos que compreendem as relações raciais brasileiras. Tais discussões devem ser inseridas nas matrizes curriculares dos cursos de graduação, além de demais atividades relacionadas ao ensino, à pesquisa e extensão, procurando visibilizar a atuação de negros e negras como produtores/as de conhecimento.

Outras duas conquistas significativas foram às legislações que instituíram reserva de vagas à população negra. A Lei 12.711/2012 que instituiu as cotas sociorracistas nas instituições federais e a Lei 12.990/2014 que institui cotas raciais em concursos públicos federais são consideradas ações pujantes no processo de descolonização dos currículos, a medida que os espaços institucionais públicos passam a contar com a presença de pessoas negras atuando enquanto discentes, docentes e profissionais públicos.

As ações apresentadas inserem-se no conjunto de políticas de ações afirmativas, “[...] isto é, conjuntos de ações políticas dirigidas à correção de desigualdades raciais e sociais, orientadas para oferta de tratamento diferenciado com vistas a corrigir desvantagens e marginalização criadas e mantidas por estrutura social excludente e discriminatória" (BRASIL, 2004: 06). Tais estratégias abrangem o amplo contingente educacional, incluindo ações desde a educação infantil ao ensino superior e, mais, propõe alterações no mercado de trabalho, espaço historicamente desigual entre negros/as e brancos/as.

As proposições políticas conquistadas pela luta da população negra expressam a capacidade de articulação, sistematização e disseminação de conteúdos que admitem as diversas formas de produção epistemológica. Isso revela a insurgência do Movimento Negro na descolonização do conhecimento de modo que transcende a teorização, por 
meio de proposições, publicações, conteúdos e metodologias que buscam romper com a estrutura epistemológica eurocêntrica. Desse modo, consideramos que sujeitos, grupos e entidades vinculadas ao Movimento Negro praticam uma postura decolonial há séculos, dentro e fora da academia, a partir de suas lutas, ações, resistências, elaborações e proposições práticas que buscam emancipar as pessoas e grupos das amarras do racismo, da branquitude, do heteropatriarcado e da colonialidade.

O impacto das ações e estratégias da política para a educação das relações étnicoraciais vem sendo demonstrado em pesquisas que identificam alterações curriculares e projetos pedagógicos com foco nas relações étnico-raciais na educação básica (GOMES, 2012; CARVALHO, 2013) e nas matrizes curriculares do ensino superior (CARDOSO, 2016; FERREIRA, 2018). Ademais, constatam mudanças epistemológicas com a presença cada vez mais significativa de discentes e docentes negros e negras nos espaços universitários, trazendo suas identidades, estéticas, valores, atitudes e diferentes modos de se produzir conhecimento (PASSOS, 2015; FONTOURA, 2017; CARVALHO, 2019).

No que tange aos cursos de Pedagogia, consideramos as transformações nas estruturas curriculares como medidas que podem possibilitar a formação de professores/as posicionados/as e compromissados/as com a luta antirracista. Na medida em que os cursos institucionalizam a abordagem étnico-racial nos seus projetos pedagógicos, programas e planos de ensino, o corpo docente passa a assumir e se responsabilizar com um ensino pautado pela dimensão racial. Tais alterações, sejam elas no currículo oficial ou no currículo em ação, potencializam a descolonização dos currículos a partir de uma perspectiva negra e brasileira (GOMES, 2019).

Nessa discussão, passaremos a evidenciar um recorte de uma pesquisa de doutorado que buscou analisar os processos que contribuíram para a institucionalização da educação das relações étnico-raciais nos currículos dos cursos de Pedagogia de três universidades federais do Sul do Brasil. Para o artigo, priorizamos o Projeto Pedagógico da UFRGS, focalizando as proposições curriculares do ensino de História que compõem o currículo do curso de Pedagogia.

\section{Abordagem decolonial no curso de Pedagogia da UFRGS: o que propõe o Ensino de História?}


O curso de Pedagogia é a segunda graduação com maior número de estudantes matriculados/as e a primeira entre as licenciaturas cursadas do Brasil (INEP, 2017). Esse curso visa formar profissionais para atuar na docência da educação infantil, nos anos iniciais do ensino fundamental, na educação de jovens e adultos, nos cursos de Ensino Médio, na modalidade normal, entre outras áreas que abrangem o trabalho pedagógico. Dentre os princípios e atividades que compreendem a docência desses/as profissionais destaca-se a consciência da diversidade étnico-racial, de gênero, de classe e de sexo assumidas nas Diretrizes Curriculares Nacionais para os cursos de Pedagogia (2005).

Formar professores e professoras politicamente posicionados contra o racismo é papel dos cursos de Pedagogia que devem problematizar e transformar suas estruturas curriculares, marcadas, historicamente, por paradigmas e autores/as eurocêntricos/as que contribuíram para a legitimação da ideologia racial. Tais perspectivas subsidiaram o Ensino de História que se constitui, também, com base em relações de poder que consolidou a Europa como o único centro capaz de produzir conhecimento. Reconhecidas teorias do âmbito das ciências sociais foram construídas a partir do privilégio epistêmico de homens brancos, inscritos num determinado contexto e realidade, fabricando um conhecimento parcial que se consolidou universal (GROSFOGUEL, 2016).

Buscando romper com uma historiografia produzida pelo cânone ocidental europeu e naturalizada como verdades científicas, as determinações advindas da obrigatoriedade do ensino de História e Cultura africana e afro-brasileira trouxeram mudanças significativas de âmbito epistemológico, metodológico, teórico e prático nos currículos institucionais. O curso de Pedagogia da UFRGS acompanhou esse processo, tendo seu documento curricular alterado e é sobre ele que vamos nos debruçar nos próximos parágrafos.

O curso de Pedagogia da UFRGS é ofertado no campus Centro, na Faculdade de Educação (FACED). Ministrado no turno da manhã, o curso oferece anualmente 120 vagas. Após a reformulação, a carga-horária do curso passou para 3.255 horas, oferecido em nove etapas/semestres, sendo 1.965 destinadas a disciplinas obrigatórias, 675 para disciplinas eletivas, 405 horas para o Estágio Docência, 90 horas para o Trabalho de Conclusão de Curso e 120 horas reservadas para atividades complementares. A organização do curso está baseada em percursos formativos constituídos por um percurso comum através da oferta de disciplinas obrigatórias e atividades que possibilitam uma formação básica e três percursos formativos, entre eles a Educação Infantil; Anos Iniciais do Ensino Fundamental e Educação de Jovens e Adultos. 
O Projeto Pedagógico de Curso Licenciatura em Pedagogia da UFRGS, datado de 2018, possui 161 páginas com textos, quadros e diversos anexos. O documento é composto das seguintes seções: perfil do curso, concepção do curso, currículo do curso, articulação entre ensino, pesquisa e extensão, sistema de avaliação do curso e política de atendimento de pessoas com necessidades especiais.

$\mathrm{Na}$ leitura do documento, identificamos alguns aspectos que contribuem com uma perspectiva de descolonização dos currículos, sobretudo ao referenciar termos como étnico-racial, descolonização dos discursos, pedagogia decolonial, interculturalidade, entre outras expressões, acompanhadas de fontes bibliográficas de cunho latinoamericano.

Sobre a implementação da Lei 10.639/2003 e das DCNERER, o curso oferta uma disciplina intitulada "Educação e relações étnico-raciais" que integra o eixo de Educação e Diversidade da matriz curricular do curso. A disciplina conta a carga-horária de 30 horas, possui caráter obrigatório na formação, sendo ofertada na sétima etapa do curso de Pedagogia. Abaixo disponibilizamos algumas informações desse componente curricular:

Quadro 1: Informações da disciplina Educação e Relações Étnico-Raciais

\begin{tabular}{|c|c|c|}
\hline Súmula & $\mathrm{C} / \mathrm{H}$ & Fase \\
\hline $\begin{array}{l}\text { Os processos educativos são instituídos e instituem-se em } \\
\text { práticas socioculturais e, no caso brasileiro, as relações étnico- } \\
\text { raciais demarcam um modo específico de expressão de } \\
\text { preconceitos e discriminações, cotidianamente } \\
\text { experimentados nos contextos escolares. Com caráter teórico- } \\
\text { prático, compreender a história das relações étnico-raciais no } \\
\text { Brasil em suas aproximações com a história da educação e as } \\
\text { práticas escolares é o objetivo central dessa disciplina. A } \\
\text { interculturalidade como chave de leitura e possibilidade de } \\
\text { compreensão da experiência educativa e os povos indígenas e } \\
\text { afro-brasileiros como tema central de estudo e reflexão. Inclui } \\
\text { atividades práticas voltadas à formação de professores. }\end{array}$ & $30 \mathrm{~h}$ & $7^{a}$ \\
\hline
\end{tabular}

Fonte: Elaborado pelas autoras ${ }^{6}, 2021$.

\footnotetext{
6 Com base no PPC do curso disponibilizado pela universidade.
} 
O currículo contempla as determinações legais para a formação inicial de professores/as, mencionando um conjunto de resoluções, normativas e portarias. Dentre elas, destacamos as Diretrizes Curriculares Nacionais para a Educação das Relações Étnico-Raciais e para o Ensino de História e Cultura Afro-Brasileira e Africana (2004) e as Diretrizes Curriculares Nacionais para a Formação de Professores Indígenas em cursos de Educação Superior e de Ensino Médio e dá outras providências (2015).

No que tange a área de História, o PPC conta com três componentes curriculares obrigatórios sistematizados no quadro abaixo:

Quadro 2- Disciplinas obrigatórias da área de história do curso de Pedagogia da UFRGS.

\begin{tabular}{|c|c|c|}
\hline Disciplina & Súmula & $\mathrm{C} / \mathrm{H}$ \\
\hline $\begin{array}{l}\text { História da Educação } \\
\text { I: modernidade e } \\
\text { interculturalidade }\end{array}$ & $\begin{array}{l}\text { Compreensão da educação, em práticas escolares e não } \\
\text { escolares, e sua expressão em processos constituídos na } \\
\text { Modernidade. Desnaturalização, pelo estudo histórico, } \\
\text { de conceitos tais como infância, família e escola. Estudo } \\
\text { dos processos de educação de povos originários da } \\
\text { América, na perspectiva da interculturalidade. } \\
\text { Reflexão sobre a potencialidade do conhecimento } \\
\text { histórico na formação da identidade docente. Introdução } \\
\text { a diferentes perspectivas de estudo da História da } \\
\text { Educação. }\end{array}$ & 60 \\
\hline $\begin{array}{l}\text { História da Educação } \\
\text { II: sujeitos, } \\
\text { instituições e práticas }\end{array}$ & $\begin{array}{l}\text { Estudo da educação e da educação escolar associadas às } \\
\text { relações de classe, gênero e etnia, enquanto } \\
\text { constituídas e constituidoras da produção e } \\
\text { reprodução } \text { das desigualdades sociais. } \\
\text { Desnaturalização da instituição escolar, a partir do } \\
\text { estudo da história das práticas e dos processos educativos } \\
\text { e da escolarização no Brasil. Compreensão dos } \\
\text { movimentos de imposição e resistência em diferentes } \\
\text { contextos e relações educativas. Aproximação com as } \\
\text { práticas e perspectivas de pesquisa em História da } \\
\text { Educação. }\end{array}$ & 45 \\
\hline
\end{tabular}




\begin{tabular}{|l|l|l|}
\hline \multirow{1}{*}{ Ensino de História } & $\begin{array}{l}\text { Possibilidades do ensino e das aprendizagens da História. } \\
\text { Ênfase na educação escolar: Educação Infantil, Anos } \\
\text { Iniciais do Ensino Fundamental e Educação de Jovens e } \\
\text { Adultos. Noções de historiografia e pesquisa histórica. } \\
\text { Tempo, espaço e grupo social: categorias fundamentais } \\
\text { para a reflexão acerca da sociedade e da natureza. } \\
\text { Desenvolvimento de noções de temporalidade e de } \\
\text { conceitos históricos, com destaque para demandas } \\
\text { contemporâneas de gênero, raça e classe. Reflexões e } \\
\text { práticas em torno das especificidades do ensino de } \\
\text { história em relação a materiais didáticos, currículo, } \\
\text { avaliação, interdisciplinaridade, patrimônio cultural e } \\
\text { inclusão, entre outros aspectos da educação escolar. } \\
\text { Inclui atividades práticas voltadas à formação de } \\
\text { professores. }\end{array}$ \\
\hline
\end{tabular}

Fonte: Autoras, 2021.

Ao analisarmos as abordagens assumidas pelas disciplinas de História, percebemos inúmeras possibilidades de interlocuções com a perspectiva da decolonialidade. A disciplina de História da Educação I, ofertada na primeira etapa do curso, prevê uma discussão acerca da modernidade e da interculturalidade, a partir dos processos de educação de sujeitos originários da América. A abertura para esse debate traz inflexões pujantes para o processo de construção do conhecimento, historicamente marcado por uma ideia de civilização que classifica e hierarquiza as diferentes formas de sociedade.

Grosfoguel (2019) expõe que a modernidade é um projeto civilizatório produzido com base na violência, difundido com a expansão colonial europeia em 1492, a partir do estabelecimento de relações de dominação entre ocidente e "não ocidente". Propor discussões sobre os processos de educação dos povos originários da América, como prevê a ementa da disciplina, permite refletir sobre os modos de colonização dos países da América Latina, caracterizado pelo controle e domínio do poder, da economia, da política e da cultura, suprimindo as narrativas das populações colonizadas.

Nessa discussão, a proposta da disciplina traz possibilidades para discutir conceitos importantes, como a ideia de colonialidade, compreendida como um modelo de poder que constituiu a modernidade e permitiu a consolidação da Europa como produtora 
universal e verdadeira dos conhecimentos científicos. Esse sistema de controle do poder, do ser e do saber balizou os diferentes campos e áreas do conhecimento, como a história, criada a partir de categorias e sistemas conceituais condicionadas a uma estrutura epistemológica ocidental que desqualificou e ignorou americanos/as, africanos/as e asiáticos/as como sujeitos do conhecimento.

A disciplina está fundamentada na perspectiva da interculturalidade, discussão central nas elaborações do pensamento decolonial. A ideia de interculturalidade, segundo Catherine Walsh (2009) tem origem nas discussões políticas trazidas pelos movimentos sociais como práticas contra-hegemônicas da lógica colonial capitalista. Tais grupos e sujeitos reivindicam as desigualdades, os processos de exclusão e dominação, propondo romper com as estruturas sociais, epistêmicas e políticas da colonialidade. A autora expõe:

De maneira ainda mais ampla, proponho a interculturalidade crítica como ferramenta pedagógica que questiona continuamente a racialização, subalternização, inferiorização e seus padrões de poder, visibiliza maneiras diferentes de ser, viver e saber e busca o desenvolvimento e criação de compreensões e condições que não só articulam e fazem dialogar as diferenças num marco de legitimidade, dignidade, igualdade, equidade e respeito, mas que - ao mesmo tempo - alentam a criação de modos "outros" - de pensar, ser, estar, aprender, ensinar, sonhar e viver que cruzam fronteiras. A interculturalidade crítica e a de-colonialidade, nesse sentido, são projetos, processos e lutas que se entrecruzam conceitualmente e pedagogicamente, alentando forças, iniciativas e perspectivas éticas que fazem questionar, transformar, sacudir, rearticular e construir. Essa força, iniciativa, agência e suas práticas dão base para o que chamo de continuação da pedagogia decolonial. (WALSH, 2009: 25).

Pautar o debate da interculturalidade permite ampliar a própria perspectiva do ensino de história, demarcada pela ênfase em paradigmas eurocêntricos que se pretendem universais. Focalizar os processos educativos a partir dos movimentos ocorridos na América possibilita conhecer e olhar para as memórias, registros e histórias de sujeitos e coletivos que, embora tenham suas vozes ignoradas, resistem às relações de poder impostas na modernidade. 
Tal perspectiva passa a ser ampliada na segunda disciplina "História da Educação II: sujeitos, instituições e práticas" ao enfatizar a relevância das dimensões de classe, etnia e gênero como constitutivas e constituidoras das desigualdades sociais. Demarcar essas categorias implica um posicionamento político do curso de Pedagogia e da disciplina de história com as relações desiguais estabelecidas nos processos de educação escolar, experienciado de diferentes modos de acordo com os lugares sociais de cada criança e jovem.

A disciplina enfatiza também a importância em compreender os movimentos de imposição das relações de poder e dominação ocorridos nesse processo, mas também, as ações de resistências criadas por sujeitos, grupos, redes e organizações, buscando confrontar as lógicas de subalternização. Estes coletivos são responsáveis por produzir, criar e propor práticas educativas emancipatórias, garantindo com que o direito à educação alcance a todas as pessoas. Por isso, estudar as práticas formuladas por diferentes grupos sociais permite conhecer outra narrativa da história do Brasil, incluindo o projeto de educação criado pelos movimentos sociais que transcende a história de educação oferecida pelo Estado.

A última disciplina obrigatória "Ensino de História" endossa a discussão ao acrescentar a categoria racial juntamente com as de classe e gênero. Embora a disciplina possua uma carga-horária de 45 horas, sua oferta ocorre em dois momentos do curso, totalizando 90 horas. Isso porque além da oferta obrigatória na sétima etapa do curso, a disciplina integra o quadro de componentes alternativos do seminário de docência escolhido pelos/as estudantes, seja ele os Anos Iniciais, a Educação de Jovens e Adultos ou a Educação Infantil. Logo, independente do percurso formativo optado, o ensino de história permeará a formação de todos/as os/as estudantes em diversas etapas do curso.

Ao apresentar possibilidades de pensar o ensino de história em articulação com a teoria e a prática nas diferentes etapas da educação básica, este componente representa papel central na formação dos/as futuros/as professores/as que terão oportunidades de criar, elaborar e proporcionar aprendizagens a partir de uma perspectiva histórica interseccional. As dimensões de gênero, raça e classe, levantadas na súmula do componente curricular, demonstram uma articulação entre categorias de opressão que marcam as desigualdades na sociedade brasileira, revelando um posicionamento interseccional assumido pela disciplina.

Para além desses componentes curriculares obrigatórios, identificamos a disciplina "Encontro de Saberes", ofertada de modo eletivo. 
Quadro 3: Informações da disciplina "Encontro de Saberes"

\begin{tabular}{|l|l|l|}
\hline \multicolumn{1}{|c|}{ Súmula } & C/H & Etapa \\
\hline $\begin{array}{l}\text { Noções de interculturalidade, diversidade cultural e pluralidade } \\
\text { epistêmica. Docência compartilhada com Mestres dos Saberes }\end{array}$ & & $\begin{array}{l}\text { Sem } \\
\text { etapa }\end{array}$ \\
$\begin{array}{l}\text { Tradicionais e Populares. Práticas interepistêmicas e intersubjetivas } \\
\text { nas artes e nas ciências humanas, naturais e sociais. Criação de } \\
\text { projetos colaborativos e de ações de intervenção social. }\end{array}$ & & \\
\hline
\end{tabular}

Fonte: Elaborado pelas autoras, 2021.

Tal disciplina é uma proposta do Núcleo de Estudos Afro-brasileiros (NEAB) da $\mathrm{UFRGS}^{7}$ e tem o intuito de "promover a educação das relações étnico-raciais através da oferta de disciplina transdisciplinar a cursos de graduação da UFRGS, contribuindo para a ampliação de critérios de seleção e de modos de desenvolvimento de temas e conteúdos escolares e para a elaboração de currículos plurais em uma perspectiva inclusiva, nãodicotômica e crítica" (NEAB/UFRGS) .

O caráter da disciplina apresenta especificidades com relação aos demais componentes curriculares, uma vez que é ministrada por mestres e mestras vinculadas a movimentos sociais, comunidades tradicionais e indígenas, por exemplo, os povos Guarani, Kaigang e Charrua que compõem o estado do Rio Grande do Sul. A disciplina, que teve início em 2016/02, está sendo ofertada semestralmente, em caráter interdisciplinar, oferecida a qualquer estudante da graduação.

A proposta dessa atividade curricular deslocaliza a produção de saberes como elaborações exclusivas da academia, reconhecendo formas outras de pensar, agir e se relacionar com o conhecimento. Nessa atividade, mestres/as, líderes e ativistas de diferentes comunidades são os sujeitos responsáveis pelas discussões na disciplina, alterando a lógica racional e universal do conhecimento ao considerar epistemologias outras. A partir da docência compartilhada entre mestres e mestras de saberes tradicionais, a atividade propõe uma relação entre os conhecimentos artísticos, naturais, sociais, matemáticos, humanos, entre outras esferas que foram historicamente fragmentadas em disciplinas.

\footnotetext{
${ }^{7}$ Esta disciplina foi inspirada na proposta elaborada pelo Prof. José Jorge de Carvalho, vinculado a Universidade de Brasília que, desde 2010, criou o Encontro de Saberes, reunindo mestres e mestras dos saberes tradicionais de diferentes regiões do país. Para maiores informações sobre esse processo, consultar Carvalho (2019).

${ }^{8}$ Excerto extraído do site do NEAB. Disponível em: https://www.ufrgs.br/neab/index.php/2018/09/28/endBh7ro-de-saberes/. Acesso em 05 de janeiro de 2021.
} 
Corroboramos com as reflexões de Carvalho (2019) ao conceber a proposta do Encontro de Saberes como um movimento de descolonização dos currículos universitários, os quais foram criados a partir de uma epistemologia ocidental e eurocêntrica do conhecimento, permitindo uma pluridiversidade entre os conhecimentos africanos, afro-brasileiros, quilombolas, indígenas, ocidentais e demais coletivos que compõem a realidade.

A partir das categorias de análise definidas, identificamos um total de cinco disciplinas integrantes da matriz curricular do curso de Pedagogia da UFRGS, sendo quatro obrigatórias e uma eletiva, que apresentam interlocuções com uma perspectiva histórica ampla, capaz de considerar os sujeitos e movimentos de luta contra as diferentes formas de colonialidade e os seus perversos efeitos. Embora esse número seja ainda muito pequeno em proporção ao quadro geral de disciplinas, consideramos as discussões, conteúdos e temáticas assumidas nesses componentes curriculares como potencializadoras de uma perspectiva decolonial.

\section{Considerações finais}

Nesse artigo, evidenciamos a insurgência do Movimento Negro na formulação de uma política para a educação das relações étnico-raciais que altera a lógica de produção do conhecimento ao reconhecer e visibilizar sujeitos e grupos étnico-raciais historicamente ignorados da estrutura epistemológica. Apresentamos as determinações legais elaboradas pelos movimentos sociais como propostas que desestabilizam o conhecimento e trazem atribuições ao campo da formação inicial de professores/as, especialmente ao curso de Pedagogia que forma docentes para atuar na Educação Básica. Além disso, tais legislações propõem modificações no ensino de História, por meio da inserção de conteúdos, valores e atitudes que rompam com uma historiografia colonialista, possibilitando o convívio de perspectivas que se relacionam e desconstroem visões eurocêntricas.

A partir dessas proposições, analisamos o PPC do curso de Pedagogia da UFRGS buscando identificar as alterações realizadas em conformidade com tais determinações, sobretudo no campo do ensino de História. Constatamos a presença de disciplinas que assumem discussões sobre as relações étnico-raciais, a interculturalidade, a pluralidade epistêmica, o encontro de saberes, além do cruzamento das dimensões de gênero, raça e classe como lentes de análise das desigualdades sociais. 
As discussões propostas pelos componentes curriculares analisados ampliam a perspectiva histórica, contribuindo com a descolonização de narrativas que contam histórias coloniais e fixam ideias particulares de raça, sexualidade, gênero e classe. Portanto, consideramos os debates, conteúdos e temáticas assumidas nas disciplinas aqui analisadas como pujantes de um processo de abertura e reconhecimento da pluralidade dos modos de conhecimentos que ultrapassam os saberes científicos, valorizando a diversidade epistemológica, cultural e política do mundo.

\section{Referências bibliográficas}

BERNARDINO-COSTA, Joaze, MALDONADO-TORRES, Nelson. GROSFOGUEL, Ramón (Orgs) (2019). Decolonialidade e pensamento afrodiaspórico. São Paulo: Autêntica.

BRASIL (2003). Lei $\mathrm{n}^{\circ} .10 .639$ de 09 de janeiro de 2003. Inclui a obrigatoriedade da temática "História e Cultura Afro-Brasileira" no currículo oficial da rede de ensino. Diário Oficial da União, Brasília.

BRASIL (2004). Parecer CNE/CP 003/2004. Diretrizes curriculares nacionais para a educação das relações étnico-raciais e para o ensino de história e cultura afrobrasileira e africana. Brasília.

BRASIL (2005). Parecer CNE/CP No5/2005. Define Diretrizes Curriculares Nacionais para o Curso de Graduação em Pedagogia. Brasília: MEC.

CARDOSO, Ivanilda Amado (2016). Educação das relações étnico-raciais: limites e possibilidades no curso de Pedagogia da UFSCar. Dissertação (Mestrado em Educação). Universidade Federal de São Carlos/SP.

CARNEIRO, Aparecida Sueli (2005). A Construção do Outro como Não-Ser como fundamento do Ser. Programa de Pós-Graduação em Educação da Universidade de São Paulo (Tese de doutorado). Feusp.

CARVALHO, Thaís Regina de (2013). Políticas de promoção da igualdade racial na Rede Municipal de Educação Infantil de Florianópolis/SC. Dissertação (Mestrado em Educação). Universidade Federal do Paraná, Curitiba.

CARVALHO, José Jorge de (2019). Encontro de Saberes e descolonização: para uma refundação étnica, racial e epistêmica das universidades brasileiras. In: BERNARDINO -COSTA, Joaze, TORRES, Nelson Maldonado, GROSFOGUEL, Ramón. (Orgs). Decolonialidade e pensamento afrodiaspórico. São Paulo: Autêntica.

FANON, Frantz (2005). Os Condenados da Terra. Tradução de Enilce Albergaria Rocha e Lucy Magalhães. $1^{\text {a }}$ reimpressão. Juiz de Fora: Ed. UFJF.

FERREIRA, Michele Guerreiro (2018). Educação das relações étnico-raciais e prática curricular de enfrentamento do racismo na UNILAB. Tese (Doutorado) Universidade Federal de Pernambuco, CE. Programa de Pós-graduação em Educação. 
FONTOURA, Maria Conceição Lopes (2017). Invasão/Ocupação da UFRGS: diálogo com docentes de cursos de licenciaturas sobre Programa de Ações Afirmativas e Educação das Relações Étnico-Raciais - ERER. Tese (Doutorado). Universidade Federal do Rio Grande do Sul, Faculdade de Educação, Programa de PósGraduação em Educação, Porto Alegre, RS.

GAUDIO, Eduarda Souza.(2021). Perspectiva negra decolonial: a insurgência de intelectuais negros/as em cursos de Pedagogia de universidades do Sul do Brasil. Tese (Doutorado em Educação). Universidade Federal de Santa Catarina, Florianópolis.

GROSFOGUEL, Ramón (2016). A estrutura do conhecimento nas universidades ocidentalizadas: racismo/sexismo epistêmico e os quatro genocídios/epistemicídios do longo século XVI. Revista Sociedade e Estado, volume 31, número 1.

GOMES, Nilma Lino (2012). As práticas pedagógicas com as relações étnico-raciais nas escolas públicas: desafios e perspectivas. In: BRASIL. GOMES, Nilma Lino (Org.). Práticas Pedagógicas de trabalho com relações étnico-raciais na escola na perspectiva da Lei $n$. 10.639/2003. Brasília: MEC, UNESCO.

GOMES, Nilma Lino (2017). O Movimento Negro Educador: saberes construídos nas lutas por emancipação. Petrópolis, RJ: Vozes.

GOMES, Nilma Lino (2019). O movimento negro e a intelectualidade negra descolonizando os currículos. In: BERBARDINO-COSTA, Joaze; MALDONADO-TORRES, Nelson; GROSFOGUEL, Ramón. (Orgs.) Decolonialidade e pensamento afrodiaspórico. Belo Horizonte: Autêntica Editora.

HOOKS, bell (2013). Ensinando a transgredir: a educação como prática da liberdade. Tradução de Marcelo Brandãi Cipolla. São Paulo: Editora Martins Fontes.

INEP (2017). Censo do Ensino Superior 2017. Disponível em: http://portal.mec.gov.br/docman/setembro-2018-pdf/97041-apresentac-a-o-censosuperior-u-ltimo/file . Acesso em 15 jan.2021.

LIMA, Fernanda da Silva.; SILVA, Karine de Souza (2020). Teorias críticas e estudos pós e decoloniais à brasileira: quando a branquitude acadêmica silencia raça e gênero. Revista Empório do Direito, São Paulo, jun. Disponível em: https://emporiododireito.com.br/leitura/teorias-criticas-e-estudos-pos-edecoloniais-a-brasileira-quando-a-branquitude-academica-silencia-raca-egenero?fbclid=IwAR3hcDVxIJ8lcGWqnb6YhnOljhFPf2wS1TIqEjIqjZ1qDHLhoYZgkkx-tc. Acesso em 10 jan. 2021.

MENESES, Maria Paula G. (2010). Corpos de violência, linguagens de resistência: as complexas teias de conhecimentos no Moçambique contemporâneo. In: SANTOS, Boaventura de Sousa.; MENESES, Maria Paula G. (Orgs.). Epistemologias do Sul. São Paulo: Cortez.

PASSOS, Joana Célia dos (2015). Relações raciais, cultura acadêmica e tensionamentos após ações afirmativas. Educação em Revista, Belo Horizonte. v.3, n.02, p. 155182.Abril-Junho. Disponível em: https://www.scielo.br/pdf/edur/v31n2/01024698-edur-31-02-00155.pdf. Acesso em 14 jan. 2021.

PASSOS, Joana Célia dos.; NOGUEIRA, João Carlos (2014). Movimento Negro, ação política e as transformações sociais no Brasil contemporâneo. Política \& Sociedade. Florianópolis, v. 13, n. 28.

QUIJANO, Anibal (2010). Colonialidade do poder e classificação social. In: SANTOS, Boaventura de Sousa.; MENESES, Maria Paula G. (Orgs.). Epistemologias do Sul. São Paulo: Cortez.

SIQUEIRA, Maria de Lourdes (2006). Intelectualidade negra e pesquisa científica. Salvador: EDUFBA. 
WALSH, Catherine (2009). Interculturalidade crítica e Pedagogia Decolonial: in-surgir, re-existir e re-viver. In.: CANDAU, Vera Maria (Org.). Educação intercultural na América Latina: entre concepções, tensões e propostas. Rio de Janeiro: Letras.

Artigo recebido em 15 de fevereiro de 2021.

Artigo aprovado em 15 de maio de 2021.

DOI: 10.12957/intellectus.2021.57817 